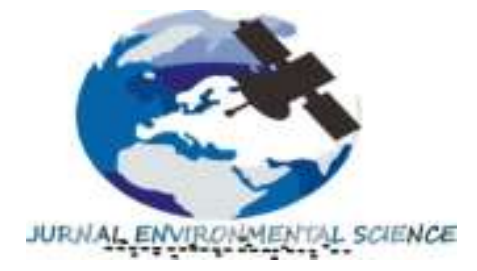

Jurnal Environmental Science

Volume 3 Nomor 1 Oktober 2020

p-ISSN : 2654-4490 dan e-ISSN : 2654-9085

Homepage at : ojs.unm.ac.id/JES

E-mail:jes@unm.ac.id

\title{
IDENTIFIKASI POTENSI PEMBANGKIT LISTRIK TENAGA MIKROHIDRO (PLTMH) SEBAGAI ENERGI TERBARUKAN DI KECAMATAN BONE-BONE KABUPATEN LUWU UTARA
}

\author{
Feby Aulia Marsida ${ }^{1}$, Ichsan Invanni ${ }^{2}, \mathrm{Uca}^{3}$ \\ Jurusan Geografi, Fakultas Matematika dan Ilmu Pengetahuan Alam \\ Universitas Negeri Makassar \\ Email:febyaulia29@gmail.com
}

\begin{abstract}
ABSTRAK
Penelitian ini bertujuan untuk mengetahui: 1). lokasi yang memenuhi kriteria untuk mengidentifikasi potensi Pembangkit Listrik Tenaga Mikrohidro (PLTMH) Kecamatan Bone-Bone. 2). Besar Daya Listrik yang dapat dibangkitkan oleh lokasi yang memenuhi kriteria dalam mengidentifikasi potensi PLTMH di Kecamatan BoneBone. 3). apakah daya listrik yang terbangkitkan dapat memenuhi kebutuhan listrik masyarakat di sekitar lokasi yang memiliki potensi PLTMH di Kecamatan Bone-Bone. hasil penelitian menunjukkan bahwa ada dua titik lokasi yang memenuhi kriteria untuk mengidentifikasi potensi PLTMH di Kecamatan Bone-Bone. Titik lokasi pertama memiliki daya listrik terbangkitkan sebesar $20 \mathrm{~kW}$ dan titik lokasi kedua memiliki daya listrik terbangkitkan sebesar 9,35 kW. Untuk kebutuhan listrik masyarakat diperkirakan sebesar 8,35 kW. Sehingga kedua titik lokasi dapat memenuhi kebutuhan listrik masyarakat.
\end{abstract}

Kata Kunci : PLTMH, daya listrik

\begin{abstract}
Mathematic and Science. Universitas Negeri Makassar (Makassar State of University).

The purpose of this study was : 1) find the location who have criteria for identification the potential of micro hydro in Bone-Bone district. 2). knowing how much electrical power will awakened from Micro hydro. 3) the electrical power that awakened of micro hydro can meet the villagers need. The result showed there are two locations have criteria for identification the potential of micro hydro in Bone-Bone district. The first location have an electrical power generated of $20 \mathrm{~kW}$ and second location have an electrical power generated of 9.35 $k W$. For the electrical villagers need are estimated at $8.35 \mathrm{~kW}$. The conclution is, the first and second location have potential for micro hidro powe plant and can meet the electrical villagers need.
\end{abstract}

Keywords : Micro Hydro, Electrical Power 


\section{PENDAHULUAN}

Energi listrik memiliki peranan yang sangat penting dalam usaha meningkatkan mutu kehidupan dan pertumbuhan ekonomi di Indonesia. Keterbatasan penyediaan energi listrik merupakan salah satu hambatan dalam pembangunan dan pengembangan masyarakat khususnya didaerah pedesaan, Sehingga menyebabkan desa-desa yang tidak tersalurkan energi listrik masih disuplai oleh generator set. Hal itu sangat tidak efisien dan boros. Untuk menghindari hal itu, berbagai macam cara dilakukan salah satunya ialah memanfaatkan energi terbarukan. Energi terbarukan adalah energi yang berasal dari sumber daya alam yang dihasilkannya tak terhabiskan dan dapat diperbarui dengan proses yang berkelanjutan. Sumber energi terbarukan ini dianggap sebagai sumber energi ramah lingkungan yang tidak mencemari lingkungan dan tidak memberikan kontribusi terhadap perubahan iklim dan pemanasan global.

Menurut data Kementerian Energi dan Sumberdaya Mineral (2009), sebagian besar kebutuhan tenaga listrik di Indonesia dipasok dari pembangkit listrik yang bersumber pada bahan bakar fosil masih menduduki peringkat tertinggi dengan presentasi 51,66\%, Gas alam menduduki peringkat kedua dengan persentase $28,57 \%$, sumber energi olahan minyak sebesar $15,34 \%$ dan energi terbarukan seperti Pembangkit listrik tenaga surya (PLTS), Pembangkit listrik tenaga angin (PLTB), Pembangkit listrik tenaga air (PLTA), dan pembangkit listrik lainya yang masih banyak dikembangkan memiliki presentase $4,43 \%$.

Pengembangaan pembangkit listrik dengan sumber energi terbarukan di Indonesia sangat menjanjikan dan memiliki prospek yang baik untuk masa depan, apalagi untuk daerah yang sulit terjangkau oleh jaringan Perusahaan Listrik Negara (PLN). khususnya di daerah-daerah pegunungan yang medannya sulit akibat bukit yang terjal dan wilayah hutan. Salah satu energi terbarukan yang dapat dimanfaatkan untuk daerah tersebut adalah Pembangkit Listrik Tenaga Mikro Hidro (PLTMH).

Pembangkit Listrik Tenaga Mikro Hidro (PLTMH), merupakan suatu implementasi dari Green Energy Initiative yaitu mendorong energi terbarukan, efisiensi energi dan energi bersih. Program pembangunan PLTMH bertujuan untuk mendorong kegiatan ekonomi masyarakat terutama di lokasi yang potensial namun belum dioptimalkan. PLTMH memiliki beberapa kunggulan dibanding dengan pembangkit listrik lainnya, bersih lingkungan, tidak konsumtif terhadap pemakaian air, lebih awet (tahan lama/long life), biaya operasinya lebih kecil dan sesuai untuk daerah terpencil (Nurhayati, 2010).

Provinsi Sulawesi Selatan ialah salah satu provinsi yang memanfaatkan Pembangkit Listrik Tenaga Mikrohidro (PLTMH) sebagai sumber listrik, khususnya di pedesaan yang sulit dijangkau oleh jaringan PLN, salah satunya ialah Kabupaten Luwu utara. Dari 11 kecamatan yang ada di Kabupaten Luwu Utara, 7 diantaranya masih memiliki daerah yang tidak terjangkau oleh Perusahaan Listrik Negara atau PLN dikarenakan akses yang sangat jauh dan medan yang sulit, salah satunya terletak di Kecamatan Bone-Bone.

Kecamatan Bone- Bone adalah salah satu kecamatan di Luwu Utara yang memiliki daerah terpencil yaitu UPT (Unit Permukiman Transmigrasi) Bantimurung, Desa Bantimurung, yang belum terjangkau oleh PLN dan masih menggunakan generator set berbahan bakar minyak. Hal itu tentu saja tidak efektif dan juga boros. Padahal Kecamatan Bone-Bone memiliki peluang besar untuk membangun Pembangkit Listrik Tenaga Mikrohidro karena kecamatan tersebut memiliki banyak sungai yang dapat dimanfaatkan sebagai energi terbarukan.

Untuk itu, Berdasarkan uraian diatas maka peneliti akan melakukan penelitian lebih lanjut mengenai Potensi Pembangkit Listrik Tenaga Mikrohidro. 


\section{METODE}

Penelitian ini akan dilakukan di UPT (Unit Permukiman Transmigrasi) Bantimurung, Desa Bantimurung, Kecamatan Bone-Bone, Kabupaten Luwu Utara. Jenis penelitian yang dilakukan ialah penelitian kuantitatif. Variabel dalam penelitian tersebut ialah Debit Aliran Sungai, Tinggi Jatuhan Air / head, Daya Terbangkitkan, dan Kebutuhan Listrik Masyarakat.

Alat yang digunakan dalam penelitian ini ialah Global positioning system, roll meter, patok/tongkat, botol plastik, stopwatch, selang plastik, dan pressure gauge.sedangkan bahan yang diguakan ialah peta administrative Kecamatan Bone-Bone dan Data Jumlah Penduduk daerah yang belum terjangkau PLN di Kecamatan Bone-Bone.

Teknik analisis data yang digunakan ialah:

1. Luas Penampang Sungai (A)

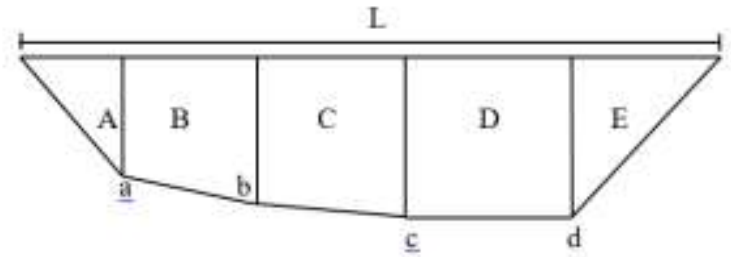

Gambar 1. Sketsa Luas Peampang Sungai

Sehingga dapat ditentukan dengan rumus :

$$
\mathrm{A}=\frac{L(a+b+c+d)}{5}
$$

Keterangan :

$$
\begin{aligned}
& \text { A }=\text { luas Penampang basah, dalam } \mathrm{m}^{2} \\
& \mathrm{~L} \quad=\text { lebar sungai, dalam } \mathrm{m} \\
& \mathrm{a}, \mathrm{b}, \mathrm{c}, \mathrm{d}=\text { kedalaman, dalam } \mathrm{m} \\
& 5=\text { jumlah pembagian interval }(\mathrm{A}, \mathrm{B}, \mathrm{C}, \mathrm{D}, \mathrm{E})
\end{aligned}
$$

2. Kecepatan Aliran (V)

Kecepatan aliran air dihitung dengan rumus:

Keterangan :

$$
\mathrm{v}=\mathrm{d} / \mathrm{t}
$$

$\mathrm{v}=$ kecepatan aliran air, dalam $\mathrm{m} / \mathrm{s}$

$\mathrm{d} \quad=$ jarak tempuh pelampung, dalam $\mathrm{m}$

$\mathrm{t} \quad=$ waktu tempuh pelampung, dalam detik

3. Debit Aliran

Debit aliran dihitung dengan rumus :

Keterangan :

$$
\mathrm{Q}=\mathrm{A} \times \mathrm{v}
$$

$\mathrm{Q}=$ debit air, dalam $\mathrm{m}^{3} / \mathrm{s}$

A $\quad=$ luas penampang aliran air, dalam $\mathrm{m}^{2}$

$\mathrm{v}=\quad$ kecepatan aliran air, dalam $\mathrm{m} / \mathrm{s}$

4. Tinggi Jatuhan Air

Tinggi jatuhan air didapat dengan rumus :

$$
\mathrm{H}=\mathrm{P} \times \mathrm{g}
$$


Keterangan:

$\mathrm{H} \quad=$ beda tinggi, dalam $\mathrm{m}$

$\mathrm{P} \quad=$ tekanan hidrostatis yang terbaca pada Pressure Gauge, dalam $\mathrm{kg} / \mathrm{cm}^{2}$

$\mathrm{g} \quad=$ Gravitasi $\left(\mathrm{m} / \mathrm{s}^{2}\right)-----9.8 \mathrm{~m} / \mathrm{s}^{2}$

atau dapat juga menggunakan :

Keterangan:

$$
\mathrm{H}=\mathrm{P} \times 2,3 \times 0,3
$$

$\mathrm{H}$ = beda tinggi, dalam $\mathrm{m}$

$\mathrm{P} \quad=$ tekanan hidrostatis yang terbaca pada Pressure Gauge, dalam psi

5. Daya Terbangkitkan

Dengan diketahuinya debit air selama beberapa waktu maka dapat ditentukan debit rancangan/desain yang akan digunakan untuk kebutuhan PLTMH. Daya yang terbangkit dapat di hitung dengan rumus :

Keterangan :

$$
P=g \times Q \times H \times \eta
$$

$\mathrm{P} \quad=$ Perkiraan daya yang dihasilkan $(\mathrm{kW})$

g $\quad=$ Gravitasi $\left(\mathrm{m} / \mathrm{s}^{2}\right)----9.8 \mathrm{~m} / \mathrm{s}^{2}$

Q $\quad=$ Debit air $\left(\mathrm{m}^{3} / \mathrm{s}\right)$

$\mathrm{H} \quad=$ Tinggi jatuhan efektif $(\mathrm{m})$

$\eta \quad=$ Efisiensi total pembangkit ---- $65 \%$

\section{HASIL DAN PEMBAHASAN}

Hasil

Desa Bantimurung ialah salah satu Desa di Kecamatan Bone-Bone yang memiliki wilayah transmigrasi bernama Unit Permukiman Transmigrasi (UPT) Bantimurung dengan luas $2,79 \mathrm{~km}^{2}$. sebagian besar penduduknya bekerja sebagai petani cengkeh. jumlah penduduknya terdiri 330 jiwa dan rumah tangganya ialah 98. (BPS Kabupaten Luwu Utara, 2018). UPT Bantimurung tergolong daerah terpencil dengan kondisi geomorfologi sebagian besar perbukitan sehingga susah dijangkau oleh Perusahaan Listrik Negara (PLN).

1. Lokasi untuk mengidentifikasi potensi PLTMH

Hal yang perlu diperhatikan untuk mendapatkan lokasi yang tepat dalam mengidentifikasi potensi PLTMH ialah adanya tinggi jatuhan air/head, debit aliran yang stabil, jarak pembangkit dengan konsumen, dan tidak terganggunya kepentingan pemakaian air. Dalam penelitian ini telah dipertimbangkan sedemikian rupa sehingga didapatkan dua titik lokasi sebagai berikut. 


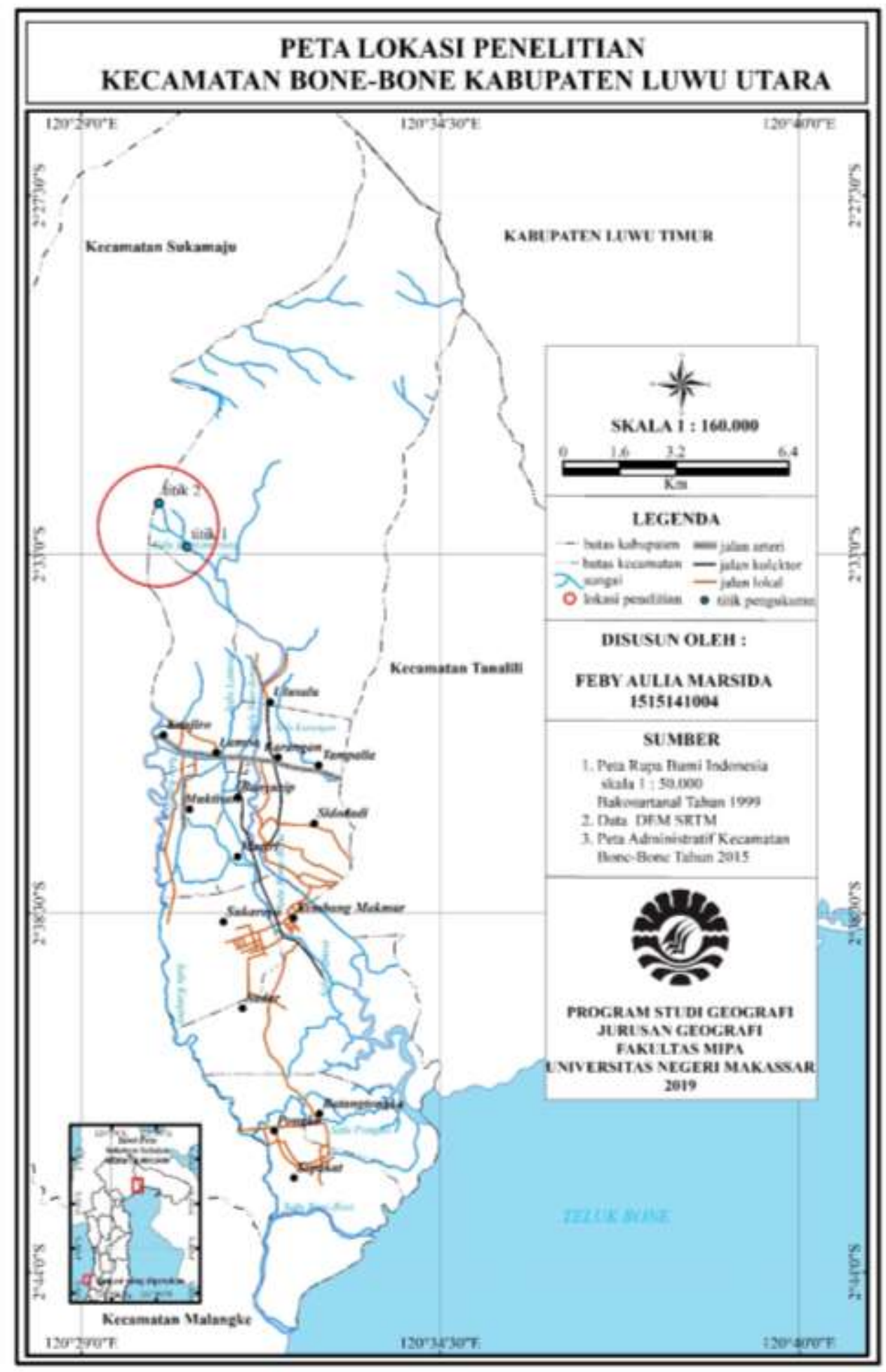


a. Tinggi jatuhan air $(\mathrm{H})$

Untuk tinggi jatuhan air didapatkan dengan menggunakan alat ukur pressure gauge, dengan hasil sebagai berikut

$$
\begin{aligned}
\text { Titik } 1 & =9,3 \text { Psi } \times 2,3 \times 0,3 \\
& =6,41 \text { meter } \\
\text { Titik } 2 & =8,2 \text { Psi } \times 2,3 \times 0,3 \\
& =5,65 \text { meter }
\end{aligned}
$$

b. Debit Aliran

Tabel 1. hasil olahan data debit aliran pada titik 1

\begin{tabular}{lcccc}
\hline & Jam 9.00 & Jam 12.00 & Jam 15.00 & Rata-rata \\
\hline $\begin{array}{l}\text { Luas penampang } \\
\text { basah (A) }\end{array}$ & 2,05 & 2,03 & 2,06 & 2,05 \\
\hline Kecepatan aliran (V) & 0,24 & 0,22 & 0,25 & 0,24 \\
\hline Debit Aliran (Q) & 0,50 & 0,46 & 0,51 & 0,49 \\
\hline
\end{tabular}

Dari hasil olahan data pada tabel 1, dapat diketahui bahwa debit aliran terkecil di titik 1 terjadi pada siang hari jam 12.00 yaitu $0,46 \mathrm{~m}^{3} / \mathrm{s}$. untuk debit aliran terbesar terjadi pada sore hari jam 15.00 yaitu dengan nilai $0,51 \mathrm{~m}^{3} / \mathrm{s}$. bila dirata-ratakan dari semua hasil pengukuran untuk titik 1, didapatkan hasil debit aliran yaitu $0,49 \mathrm{~m}^{3} / \mathrm{s}$.

Tabel 2. hasil olahan data debit aliran pada titik 2

Jam 9.00 Jam 12.00 Jam $15.00 \quad$ Rata-rata

\begin{tabular}{lcccc}
\hline $\begin{array}{l}\text { Luas penampang } \\
\text { basah (A) }\end{array}$ & 1,20 & 1,18 & 1,20 & 1,19 \\
\hline Kecepatan aliran (V) & 0,22 & 0,20 & 0,22 & 0,21 \\
\hline Debit Aliran (Q) & 0,26 & 0,24 & 0,27 & 0,26
\end{tabular}

Kemudian untuk hasil olahan data pada tabel 2, didapatkan bahwa debit aliran terkecil di titik 1 terjadi pada siang hari jam 12.00 yaitu $0,24 \mathrm{~m}^{3} / \mathrm{s}$. untuk debit aliran terbesar terjadi pada sore hari jam 15.00 yaitu dengan nilai $0,27 \mathrm{~m}^{3} / \mathrm{s}$. bila dirata-ratakan dari semua hasil pengukuran untuk titik 2 , didapatkan hasil debit aliran yaitu $0,26 \mathrm{~m}^{3} / \mathrm{s}$. 
2. Besar Daya Listrik yang dihasilkan

Tabel 3. daya listrik yang terbangkitkan berdasarkan olahan data primer pada titik 1

Jam 9.00 Jam $12.00 \quad$ Jam $15.00 \quad$ Rata-rata

\begin{tabular}{ccccc}
\hline $\begin{array}{c}\text { Percepatan gravitasi } \\
\left(\mathrm{m} / \mathrm{s}^{2}\right)\end{array}$ & 9,80 & 9,80 & 9,80 & 9,80 \\
$\begin{array}{c}\text { Debit aliran air (Q) } \\
\text { Tinggi jatuhan efektif }\end{array}$ & 0,50 & 0,46 & 0,51 & 0,49 \\
$(\mathrm{H})$ & 6,41 & 6,41 & 6,41 & 6,41 \\
Efisiensi total pembangkit & 0,65 & 0,65 & 0,65 & 0,65 \\
\hline Daya terbangkitkan $(\mathbf{k W})$ & 20,41 & 18,78 & 20,82 & $\mathbf{2 0 , 0 0}$ \\
\hline
\end{tabular}

Berdasarkan tabel 3, diketahui bahwa daya yang dapat dibangkitkan pada titik 1 berdasarkan rata-rata ialah sebesar $20 \mathrm{~kW}$. Hal tersebut menunjukkan bahwa di lokasi tersebut memiliki potensi untuk PLTMH atau Pembangkit Listrik Tenaga Mikrohidro, karena untuk PLTMH itu sendiri potensi daya listrik yang harus dipenuhi ialah sebesar $5-100 \mathrm{~kW}$.

Tabel 4.9 daya listrik yang terbangkitkan berdasarkan olahan data primer pada titik 2

Jam 9.00 Jam $12.00 \quad$ Jam $15.00 \quad$ Rata-rata

\begin{tabular}{ccccc}
\hline $\begin{array}{c}\text { Percepatan gravitasi } \\
\left(\mathrm{m} / \mathrm{s}^{2}\right)\end{array}$ & 9,80 & 9,80 & 9,80 & 9,80 \\
$\begin{array}{c}\text { Debit aliran air (Q) } \\
\text { Tinggi jatuhan efektif }\end{array}$ & 0,26 & 0,24 & 0,27 & 0,26 \\
$(\mathrm{H})$ & 5,65 & 5,65 & 5,65 & 5,65 \\
Efisiensi total pembangkit & 0,65 & 0,65 & 0,65 & 0,65 \\
Daya terbangkitkan $(\mathbf{k W})$ & 9,35 & 8,63 & 9,71 & $\mathbf{9 , 3 5}$ \\
\hline
\end{tabular}

Berdasarkan tabel 4, diketahui bahwa daya yang dapat dibangkitkan pada titik 2 berdasarkan rata-rata ialah sebesar 9,35 kW. Hal tersebut menunjukkan bahwa di lokasi tersebut memiliki potensi untuk PLTMH atau Pembangkit Listrik Tenaga Mikrohidro, karena untuk PLTMH itu sendiri potensi daya listrik yang harus dipenuhi ialah sebesar $5-100 \mathrm{~kW}$.

3. Kebutuhan Listrik Masyarakat

Untuk menghitung seberapa besar kebutuhan listrik masyarakat UPT Bantimurung, maka terlebih dahulu agar mensurvei berapa jumlah rumah yang masih ditempati, jumlah sekolah, jumlah fasilitas keagamaan seperti masjid, dan fasilitas kesehatan. Sehingga untuk kebutuhan listrik dapat dilihat sebagai berikut. 
Tabel 5. perkiraan kebutuhan daya listrik masyarakat UPT Bantimurung

\begin{tabular}{|c|c|c|c|}
\hline Keterangan & Jumlah & Daya & Jumlah daya \\
\hline \multicolumn{4}{|l|}{ Sambungan Rumah } \\
\hline$>$ Penerangan Lampu & $42 \times 4$ titik & 20 watt & 3.360 watt \\
\hline$>$ Televisi & 42 unit & 100 watt & 4.200 watt \\
\hline \multicolumn{4}{|l|}{ Sekolah } \\
\hline P Penerangan Lampu Luar & $2 \times 3$ titik & 20 watt & 120 watt \\
\hline \multicolumn{4}{|l|}{ Masjid } \\
\hline$>$ Penerangan Lampu & 6 titik & 20 watt & 120 watt \\
\hline$>$ Amplifier & 1 buah & 200 watt & 200 watt \\
\hline$>$ Pengeras suara/toa & 1 buah & 100 watt & 100 watt \\
\hline \multicolumn{4}{|l|}{ Pustu (Puskesmas Pembantu) } \\
\hline$>$ Penerangan Lampu & 5 titik & 20 watt & 100 watt \\
\hline$>$ Lemari Pendingin & 1 buah & 150 watt & 150 watt \\
\hline \multicolumn{3}{|l|}{ TOTAL } & $\begin{array}{l}8.350 \text { watt } \\
\mathbf{8 , 3 5} \mathbf{k W}\end{array}$ \\
\hline
\end{tabular}

Berdasarkan tabel 5, diketahui bahwa kebutuhan listrik masyarakat UPT Bantimurung diperkirakan mencapai 8.350 watt atau $8,35 \mathrm{~kW}$. Hal tersebut menunjukkan bahwa lokasi titik 1 yang memiliki potensi daya listrik $20 \mathrm{~kW}$ dapat memenuhi kebutuhan listrik masyarakat yang ada di UPT Bantimurung. Begitupun juga dengan lokasi titik 2 yang memiliki potensi daya listrik sebesar 9,35 $\mathrm{kW}$. Dengan demikian diketahui bahwa lokasi titik 1 maupun titik 2 memiliki potensi untuk PLTMH dan juga memenuhi kebutuhan listrik masyarakat UPT Bantimurung.

Terkhusus untuk lokasi titik 1 dapat menghasilkan daya sebesar $20 \mathrm{~kW}$ sehingga daya tersebut sangat mencukupi kebutuhan listrik masyarakat, bahkan masih memiliki sisa $11.65 \mathrm{~kW}$ yang dapat digunakan jangka panjang bila ada penambahan penduduk ataupun fasilitas lain.

\section{SIMPULAN}

Berdasarkan hasil dan pembahasan, maka penelitian dapat disimpulkan sebagai berikut:

Untuk mendapatkan lokasi yang tepat dalam mengidentifikasi potensi PLTMH perlu memperhatikan tinggi jatuhan air/head, debit aliran yang stabil, jarak pembangkit dengan konsumen yang umumnya $2 \mathrm{~km}$, dan tidak terganggunya kepentingan pemakaian air seperti keperluan air bersih, Besar daya yang terbangkitkan di lokasi pengukuran titik 1 sebesar $20 \mathrm{~kW}$ dan di titik 2 sebesar 9,35 kW. Masing-masing dari besar daya tersebut memiliki potensi untuk PLTMH atau Pembangkit Listrik Tenaga Mikrohidro, karena untuk dapat dikatakan sebagai PLTMH potensi daya listrik yang harus dipenuhi ialah sebesar $5-100 \mathrm{~kW}$, Kebutuhan listrik masyarakat UPT Bantimurung diperkirakan mencapai 8.350 watt atau $8,35 \mathrm{~kW}$. Hal tersebut menunjukkan bahwa lokasi pengukuran titik 1 yang memiliki potensi daya listrik sebesar $20 \mathrm{~kW}$ dapat memenuhi kebutuhan listrik masyarakat yang ada di UPT Bantimurung. Begitupun juga dengan lokasi pengukuran titik 2 yang memiliki potensi daya listrik sebesar 9,35 kW dapat memenuhi kebutuhan listrik masyarakat UPT Bantimurung. 


\section{DAFTAR RUJUKAN}

Arismunandar, Kuwahara S. 1974. Pembangkitan dengan Tenaga Air, Buku Pegangan Teknik Tenaga Listrik, Jilid I. Jakarta (ID) : Pradnya Paramita

Asdak, Chay. 2007. Hidrologi dan Pengelolaan Daerah Aliran Sungai. Yogyakarta: Gadjah Mada University Press

Badan Pusat Statistik Kabupaten Luwu Utara. (2018). Kecamatan Bone-Bone Dalam Angka 2018, Luwu Utara

Harvey, A. 1993. Micro - Hydro Design Manual: A Guide to small - scale Waterpower Schemes. IT Publications, London

Kementrian ESDM 2009. Pedoman studi kelayakan Hidrologi. program Direktorat Jendral Listrik dan Pemanfaatan Energi Departemen Energi dan Sumberdaya Mineral.Jakarta.

Kementrian ESDM 2010. Modul Pelatihan studi kelayakan Mikrohidro. Integreated microhydo depelopment program Direktorat Jendral Listrik dan Pemanfaatan Energi Departemen Energi dan Sumberdaya Mineral. Jakarta.

M. Woro. Nugroho. 2009. Studi Potensi Kelayakan Saluran Irigasi Kabupaten Klaten Sebagai PLTMH Dengan Analisa Dan Rancangan Bangun Kincir Ismun. Tesis. Yogyakarta :Fakultas Teknik, Universitas Gadjah Mada

Moh. Nazir. 2011. Metode Penelitian. Bogor: Ghalia Indonesia

Nurhayati. 2010. Analisis Potensi Pengembangan Pembangkit Listrik Tenaga Mikrohidro Di Kabupaten Bone Bolango. Fakultas Teknik, Universitas Gorontalo

Peraturan Pemerintah Republik Indonesia Nomor 3 Tahun 2005 Tentang Perubahan Atas Peraturan Pemerintah Nomor 10 Tahun 1989 Tentang Penyediaan Dan Pemanfaatan Tenaga Listrik.

PNPM, 2010. Buku Panduan Energi yang Terbarukan. Tim contained energy Indonesia, Jakarta.

Prayogo, E. 2003. Teknologi Mikrohidro dalam Pemanfaatan Sumber Daya Air untuk Menunjang Pembangunan Pedesaan. Semiloka Produk-produk Penelitian Departement Kimpraswill. Makassar

Ridwansyah, Iwan. 2015. Potensi Sumberdaya air untuk PLTMH di DAS Cisadene Hulu berdasararkan metode hidrologi SWAT. IPB. Bogor

Rompas P. 2011. Analisis pembangkit listrik tenaga mikrohidro (PLTMH) pada daerah aliran Sungai Ongkak Mongondow di Desa Muntoi Kabupaten Bolang Mongondow. Jurnal Penelitian Saintek.

Soewarno. 1991. Hidrologi Pengukuran dan Pengolahan Data Aliran Sungai (Hidrometri). Bandung 